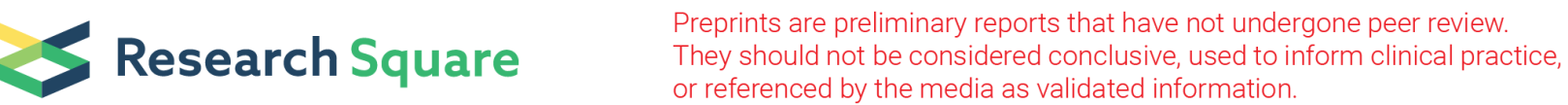

\section{Three-dimensional Printing Versus Conventional Machining in the Creation of a Meatal Urethral Dilator: a Cost and Mechanical Strength Analysis}

Michael Yue-Cheng Chen ( $\nabla$ michaelyuechengchen@hotmail.com )

Queensland University of Technology https://orcid.org/0000-0001-8294-6876

Jacob Skewes

Queensland University of Technology

Ryan Daley

Queensland University of Technology

Maria Ann Woodruff

Queensland University of Technology

Nicholas John Rukin

Redcliffe Hospital

\section{Research}

Keywords: Three-Dimensional Printing, Urology, Urethral Stricture, Intermittent Urethral Catheterization

Posted Date: May 15th, 2020

DOI: https://doi.org/10.21203/rs.3.rs-28817/v1

License: (c) (1) This work is licensed under a Creative Commons Attribution 4.0 International License.

Read Full License

Version of Record: A version of this preprint was published on July 1st, 2020. See the published version at https://doi.org/10.1186/s12938-020-00799-8. 


\section{Abstract}

\section{Background}

Three-dimensional (3D) printing is a promising technology but the limitations are often poorly understood. We compare different 3D printingmethods with conventional machining techniques in manufacturing meatal urethral dilators which were recently removed from the Australian market.

\section{Methods}

A prototype dilator was 3D printed vertically orientated on a low cost fused deposition modelling (FDM) 3D printer in polylactic acid (PLA) and acrylonitrile butadiene styrene (ABS). It was also 3D printed horizontally orientated in ABS on a high-end FDM 3D printer with soluble support material, as well as on a SLS 3D printer in medical nylon. The dilator was also machined in stainless steel using a lathe. All dilators were tested mechanically in a custom rig by hanging calibrated weights from the handle until the dilator snapped.

\section{Results}

The horizontally printed ABS dilator experienced failure at a greater load than the vertically printed PLA and ABS dilators respectively ( $503 \mathrm{~g}$ vs $283 \mathrm{~g}$ vs $163 \mathrm{~g}, \mathrm{p}<0.001$ ). The SLS nylon dilator and machined steel dilator did not fail. The steel dilator is most expensive with a quantity of five at 98 USD each, but this decreases to 30 USD each for a quantity of 1000. In contrast, the cost for the SLS dilator is 33 USD each for five and 27 USD each for 1000 .

\section{Conclusions}

At the current time 3D printing is not a replacement for conventional manufacturing. 3D printing is best used for patient-specific parts, prototyping or manufacturing complex parts that have additional functionality that cannot otherwise beachieved.

\section{Background}

Three-dimensional (3D) printing, or additive manufacturing, is a promising technology that can create complex 3D structures layer by layer and is increasingly being used in biomedical and urological research to create patient-specific and geometrically complex constructs in an economical way(1). There are a wide variety of 3D printing techniques now available. Fused deposition modelling (FDM) printing is the most commonly used and lowest cost approach since the expiry of patents. In describing the low cost of 3D printing, many medical research papers quote a price of USD 300 for a 3D printer (2-4). However, many clinicians may be unaware of the quality of print that can be achieved with such a low cost 3D printing method when compared to conventional manufacturing. In our experience, to achieve a consistent result with low cost FDM printing a printer cost of 1000 to 3000 USD is more realistic. 
Instead of FDM, research groups frequently employ more advanced 3D printing methods such as stereolithography (SLA) or selective laser sintering (SLS). For example, in the field of urology, many groups have explored the use of 3D printed prostate and kidney models using SLA technology (5-7).

Increasingly, researchers are also exploring the potential for 3D printing in creating surgical equipment. This includes basic equipment such as forceps (8) and retractors (9) which are currently mass manufactured using conventional methods. Whilst interesting, this raises the question of whether 3D printing these basic devices will be cost-effective or clinically safe.

Meatal stenosis is an abnormal narrowing of the urethral meatus which is the distal opening of the urethra. It can arise secondary to skin disorders or instrumentation injury. For example the incidence of meatal stenosis following circumcision is around $7-11 \%(10,11)$. Self-dilatation by patients at home is often used as a treatment option in the initial stages with surgery reserved for persisting issues $(12,13)$.

The Cook@ meatal dilator we used at our institutions was recently removed from the Australian market and is no longer available. This prompted us to explore the production of a new meatal dilator which we could potentially 3D print in-house at our institution. Meatal dilators are used by patients at home and do not have to be sterile, thus being a simple low-risk device with which to compare manufacturing methods (13). In this study, we compare cost and mechanical strength of dilators made with four approaches: i) lowest cost FDM 3D printing of a vertically orientated dilator, ii) horizontally orientated dilator on a higher quality FDM 3D printer, iii) the more advanced 3D printing technique of SLS and iv) conventional lathe machining.

\section{Results}

\section{Dilator creation}

One issue encountered during the FDM printing process of the vertically orientated dilators was that each layer at the tip was so small that there was insufficient time for the material to cool after extrusion. In addition, the tiny layers led to some instability of the part which meant the fine details at the tip were not accurately printed (Fig. 1). In contrast, the horizontally printed ABS dilator was able to be printed smoothly with the addition of dual extrusion soluble support material.

The SLS nylon dilator printed without issue. All 3D printed dilators were smoothed with sandpaper. The machined steel dilator was manufactured without issue and polished to smooth the surface (Fig. 4).

\section{Mechanical testing}

All three FDM printed prototype meatal dilators snapped cleanly during testing (Table 1). As expected, the horizontally printed $A B S$ dilator was more ductile than the vertically printed $A B S$ and PLA dilators respectively ( $503 \mathrm{~g}$ vs $283 \mathrm{~g}$ vs $163 \mathrm{~g}, \mathrm{p}<0.001$ ). Figure 5 shows just before breaking how the ductility of the horizontally printed ABS dilator allows it to bend to a far greater degree. 
The SLS nylon dilator was unexpectedly strong and elastic and did not fail during our mechanical testing with calibrated weights. When the weight reached around $1000 \mathrm{~g}$, the dilator elastically deformed and slipped out of the rig. When approximately $5000 \mathrm{~g}$ of manual force was directly applied to the nylon dilator tip, it did not snap but began to bend (Fig. 2). As expected, the steel dilator was not able to be bent or snapped even when approximately $10,000 \mathrm{~g}$ was manually to the tip.

\section{Cost analysis}

Table 1 summarises the comparison between the dilator types in terms of various costs. Assuming an order quantity of five from an external company, conventional machining is more costly than 3D printing with a unit price of USD 98. However, if we assume a quantity of 1,000 then the unit price of the stainless steel dilators drops to around USD 30. 3D printing does not have the same benefit in producing large quantities and the unit price plateaus at a quantity of around 100 parts. For example, the SLS nylon dilators cost USD 33 each for a quantity of five, but USD 27 each for a quantity of 100 which then plateaus.

Table 1

Summary of comparison between different meatal urethral dilators in cost and mechanical strength

\begin{tabular}{|c|c|c|c|c|c|c|c|}
\hline Prototype & $\begin{array}{l}\text { Material } \\
\text { cost } \\
\text { USD }\end{array}$ & $\begin{array}{l}\text { Printer / } \\
\text { machine } \\
\text { cost, } \\
\sim \text { USD }\end{array}$ & $\begin{array}{l}\text { Printer / } \\
\text { machine } \\
\text { cost, } \\
\sim \text { USD }\end{array}$ & $\begin{array}{l}\text { Total } \\
\text { labour } \\
\text { time, } \\
\text { hours }\end{array}$ & $\begin{array}{l}\text { Cost per dilator } \\
\text { (assuming } \\
\text { order quantity } \\
\text { of } 5 \text { ) }\end{array}$ & $\begin{array}{l}\text { Failure } \\
\text { angle, } \\
\text { degrees }\end{array}$ & $\begin{array}{l}\text { Maximum } \\
\text { weight in } \\
\text { grams, } \\
\text { mean } \\
\text { (SD), }\end{array}$ \\
\hline $\begin{array}{l}\text { Vertical } \\
\text { ABS }\end{array}$ & 1 & $\begin{array}{l}\text { Ultimaker } \\
2+\end{array}$ & 2500 & 3 & 12 & 12 & 283 (15) \\
\hline $\begin{array}{l}\text { Vertical } \\
\text { PLA }\end{array}$ & 1 & $\begin{array}{l}\text { Ultimaker } \\
2+\end{array}$ & 2500 & 3 & 11 & 10 & $163(51)$ \\
\hline $\begin{array}{l}\text { Horizontal } \\
\text { ABS }\end{array}$ & 6 & $\begin{array}{l}\text { Fortus } \\
400\end{array}$ & 185,000 & 4 & 45 & 40 & $503(6)$ \\
\hline $\begin{array}{l}\text { SLS } \\
\text { Nylon }\end{array}$ & 3 & $\begin{array}{l}\text { Formiga } \\
\text { P100 }\end{array}$ & 175,000 & 1.5 & 33 & $\begin{array}{l}\text { No } \\
\text { failure }\end{array}$ & $>5000$ \\
\hline $\begin{array}{l}\text { Machined } \\
\text { stainless } \\
\text { steel }\end{array}$ & 4 & $\begin{array}{l}\text { HAFCO } \\
\text { metal } \\
\text { master } \\
320-G\end{array}$ & 2400 & 0.75 & 98 & $\begin{array}{l}\text { No } \\
\text { failure }\end{array}$ & $>10,000$ \\
\hline
\end{tabular}

\section{Discussion}

$3 \mathrm{D}$ printing is a promising new technology that has the potential to revolutionise medicine. Many noninvasive uses for 3D printing in urology have been explored ranging from surgical simulation (14-17), histopathological correlation $(18,19)$, augmented reality surgery $(20,21)$ and anatomical models $(5,6$, 22-25). However, the next frontier in 3D printing research is the development of clinically useful 3D printed equipment, tools and implants. Oft-quoted low cost FDM 3D printers costing USD 300 suggest 
low barriers for this goal. To that end, some have begun exploring whether 3D printing could be used to create basic surgical equipment $(8,9)$. However, many clinicians are unaware of the limitations of low cost FDM 3D printing and the strengths of conventional manufacturing techniques.

Whilst FDM printing can be low cost and accessible to hospitals around the world, the quality of the parts produced may not be mechanically consistent enough, particularly in healthcare where standards of safety are high. To produce higher quality parts, the setup cost of a 3D printer or machine will be much higher such as the SLS printer used in this study which costs approximately USD 175,000. It is therefore unlikely that individual institutions will be able to use low cost FDM 3D printing to manufacture devices in-house at a quality that is clinically safe and reliable.

One of the difficulties in designing this study was the lack of data on what threshold of mechanical strength would be needed. Although the use of intermittent self-catheterisation to prevent stricture recurrence is established in the literature (26), most studies are focused on dilatation using long urethral catheters rather than the short meatal dilator in our study. In fact, the literature on meatal dilators is extremely limited (13). Therefore, our design aims to stress the dilator at its weakest point, although this may not occur in clinical practice. Based on clinical experience we are confident that the SLS dilator not breaking even at $5,000 \mathrm{~g}$ of force is sufficiently safe for clinical use. Even the horizontal ABS dilator which could take $500 \mathrm{~g}$ of weight and only failed at a 40 degree bend would likely be safe as a patient is unlikely to bend the dilator to that angle during use in the urethra. If a portion of the dilator did snap it would need to be retrieved via flexible cystoscopy by a urologist under local anaesthetic with overall minimal morbidity to the patient.

The strengths of 3D printing are in the creation of patient-specific parts, manufacturing complex parts which conventional methods cannot achieve, or prototyping. Despite the enormous potential of the technology, 3D printing should not be viewed yet as a replacement for conventional manufacturing techniques. This is especially true for parts needed in high quantities with simple geometry such as the dilator. For example, the quoted unit price of five machined steel dilators is around USD 98, but the unit price if ordering a quantity of 1000 becomes around USD 30. It is also worth noting that with modern machining parts with simple geometry such as the dilator can also be made to be patient-specific, particularly with the aid of computer numerical controlled (CNC) machining (27).

In the urological field, Park et al (28) used 3D printing to create a ureteric stent prototype which prevented reflux in vitro. This is a valid use of 3D printing to prototype a part in small quantities. However, if such a prototype entered mainstream use then 3D printing would not necessarily be the best method to continue production. Del Junco et al (29) tested 3D printed ureteric stents and laparoscopic trochars in porcine models and concluded it was feasible, despite the initial functional failures they described and with no discussion on cost.

3D printing in medicine has perhaps advanced the most in the field of orthopaedic surgery. 3D-printed acetabular cups demonstrate the strengths of 3D printing that we have discussed as they can be patient- 
specific but also they are highly porous to encourage bone ingrowth which conventional manufacturing cannot achieve (30), however the long term outcomes remain to be seen.

Our study is one of the first to examine the practicalities of using 3D printing techniques to produce low risk clinically applicable medical devices such as the urethral meatal dilator. Whilst many clinicians may be aware of how low cost 3D printing can be, we hope to show that there are limitations to this technology. 3D printing medical research should not seek to replace all conventional techniques in producing simple devices but instead capitalise on the advantages of 3D printing in creating complex geometries or patient-specific parts. To our knowledge, this is also the first project to investigate a method for mechanically testing the strength of urethral dilators.

In this study we have compared different materials as well as different manufacturing methods. This was necessary due to the practicalities of each method, for example low cost FDM printing cannot be used to 3D print in metals. We have performed relatively simple mechanical testing which would be suitable for a low risk device such as a meatal urethral dilator. However, higher risk devices that are required to be sterile would need more rigorous testing. Any discussion around cost is likely to change in the future as $3 \mathrm{D}$ printing technology continues to evolve and become cheaper and more accessible. Our quoted prices are from single commercial sources which should be taken as approximations only, valid at the present time (2019).

\section{Conclusions}

3D printing is not a replacement for all conventional manufacturing techniques. Although low cost FDM printing technology is easily accessible, the meatal urethral dilators created were mechanically weak and their quality was too inconsistent for clinical use. Higher quality 3D printing options such as SLS are available but are more costly. 3D printing in medicine should be reserved for patient-specific parts, prototyping, or complex parts that add functionality that cannot be achieved with conventional manufacturing.

\section{Methods}

\section{Prototype design}

A prototype meatal dilator was created using computer-aided design (CAD) on software Fusion 360 (Autodesk, San Rafael, U.S.). The dilator, excluding the handle, is $90.0 \mathrm{~mm}$ in length with a diameter starting from $2.0 \mathrm{~mm}$ (6 French) at the tip and $10.7 \mathrm{~mm}$ (32 French) at the base (Fig. 3). A handle was added which was designed to be curved to help facilitate machining. This design process took approximately one hour. The design was done in collaboration with an experienced urethral surgeon who approved the shape, diameter and length.

\section{Fused Deposition Modelling}


FDM extrudes thermoplastic material via a heated nozzle layer by layer and thus it requires printing of support material for any overhanging areas. Therefore, the easiest way to 3D print the dilator prototype without supports is to print it orientated vertically. However, the orientation of a FDM print affects the mechanical properties as the part will be weakest between each layer (Fig. 4). Therefore, a horizontally orientated dilator would be less likely to snap but would require a more complex and costly 3D printing process.

The prototype dilator was initially 3D printed with a low cost FDM technique using polylactic acid (PLA) and acrylonitrile butadiene styrene (ABS) orientated vertically. PLA and ABS are the two most common materials used in 3D printing (31). As we found ABS to be more ductile than PLA as expected, we then printed in ABS orientated horizontally on a higher quality FDM printer using soluble support material. The vertical PLA and ABS dilators were printed on an Ultimaker 2+ (Ultimaker B.V., Geldermalsen, Netherlands) while the horizontal ABS dilators were printed on the Fortus 400 (Stratasys, Eden Prairie, U.S.) which allows dual extrusion of the ABS filament and also a soluble support filament that can be removed after the print is completed.

\section{Selective laser sintering}

A SLS technique was used to 3D print in nylon (polyaurinlactam 2200). This material is approved for medical use and bio compatible according to EN ISO 10993-1 and USP/level VI/121 ${ }^{\circ} \mathrm{C}$ standards. The SLS technique uses a laser to fuse powder particles layer by layer which helps create a part with more isotropic mechanical properties, with less weakness between layers found in FDM printing. In addition, highly complex parts can be printed without supports. The SLS 3D printer used was the Formiga P100 (EOS, Munich, Germany).

\section{Conventional machining}

The dilator was also manufactured using a manual lathing process in medical grade $316 \mathrm{~L}$ stainless steel on a HAFCO Metal Master 350 lathe (Hare \& Forbes, Sydney, Australia). This process was chosen because the geometry of the dilator is symmetrical and revolute around its central axis.

Using a lathe to reshape a bar of steel into the desired shape, a material volume wastage of approximately $60 \%$ can be expected, as opposed to a possible $0 \%$ when compared to 3D printing.

\section{Mechanical testing}

To test the mechanical strength of the dilators, we created a "worst-case scenario" in which all the mechanical stress was concentrated at the tip where it is weakest. A custom rig was constructed using a laser cut acrylic to hold the dilator (Fig. 5). The acrylic has markings to display the bending angle of the dilator. A strip of polyurethane is placed at the bottom of the dilator tip to provide a softer surface, more similar to urethra. Calibrated test weights were then hung from the handle end of the dilator in increasing amounts. The process was video recorded to estimate the breaking angle and weight of the dilators. Each type of dilator was tested three times. 


\section{Analysis}

The primary outcomes were the cost of the dilators and their mechanical strength. The cost analysis of the dilators and 3D printers was based on prices quoted by 3D printing distribution companies. Cost per dilator was based on an assumption of an institution ordering a quantity of five dilators from a company offering 3D printing or machining. Mean and standard deviation breaking weight were calculated for the three tests on each dilator type. One-way ANOVA was used to determine statistical significance using Stata (StataCorp. 2017. Stata Statistical Software: Release 15. College Station, TX: StataCorp LLC).

\section{List Of Abbreviations}

Three-dimensional printing (3D printing)

Fused deposition modelling (FDM)

Stereolithography (SLA)

Selective laser sintering (SLS)

Acrylonitrile butadiene styrene (ABS)

Polylactic acid (PLA)

Computer aided design (CAD)

\section{Declarations}

\section{Ethics approval and consent to participate:}

Not applicable

\section{Consent for publication:}

Not applicable

\section{Availability of data and materials:}

Data sharing is not applicable to this article as no datasets were generated or analysed during the current study.

\section{Competing interests:}


The authors declare that they have no competing interests

\section{Funding:}

This research was funded by the Herston Biofabrication Institute, a publicly government funded institute of clinicians and researchers. No funding from external funding bodies was received.

\section{Authors' contributions:}

MC developed the ideas for the project, collected data and performed mechanical testing, cost analysis, statistical analysis and wrote the manuscript. JS designed the dilator, performed mechanical testing, made the figures and assisted in the manuscript. RD produced the steel dilator and assisted in the manuscript. MW and NR provided supervision, guidance and assistance in writing the manuscript. All authors have read and approved the manuscript.

\section{Acknowledgement:}

None

\section{References}

1. Chen MY, Skewes J, Desselle M, Wong C, Woodruff MA, Dasgupta P, et al. Current applications of three-dimensional printing in urology. BJU Int. 2020;125(1):17-27.

2. Coles-Black J, Chao I, Chuen J. Three-dimensional printing in medicine. Med J Aust. 2017;207(3):102-3.

3. Colaco M, Igel DA, Atala A. The potential of 3D printing in urological research and patient care. Nature reviews Urology. 2018;15(4):213-21.

4. Ventola CL. Medical Applications for 3D Printing: Current and Projected Uses. P T. 2014;39(10):70411.

5. Porpiglia F, Bertolo R, Checcucci E, Amparore D, Autorino R, Dasgupta P, et al. Development and validation of 3D printed virtual models for robot-assisted radical prostatectomy and partial nephrectomy: urologists' and patients' perception. World J Urol. 2018;36(2):201-7.

6. Wake N, Rosenkrantz AB, Huang R, Park KU, Wysock JS, Taneja SS, et al. Patient-specific 3D printed and augmented reality kidney and prostate cancer models: impact on patient education. 3D Printing in Medicine. 2019;5(1):4.

7. Chandak P, Byrne N, Lynch H, Allen C, Rottenberg G, Chandra A, et al. Three-dimensional printing in robot-assisted radical prostatectomy - an Idea, Development, Exploration, Assessment, Long-term follow-up (IDEAL) Phase 2a study. BJU Int. 2018;122(3):360-1. 
8. George M, Aroom KR, Hawes HG, Gill BS, Love J. 3D Printed Surgical Instruments: The Design and Fabrication Process. World J Surg. 2017;41(1):314-9.

9. Rankin TM, Giovinco NA, Cucher DJ, Watts G, Hurwitz B, Armstrong DG. Three-dimensional printing surgical instruments: are we there yet? J Surg Res. 2014;189(2):193-7.

10. Stenram A, Malmfors G, Okmian L. Circumcision for phimosis: a follow-up study. Scand J Urol Nephrol. 1986;20(2):89-92.

11. Van Howe RS. Incidence of meatal stenosis following neonatal circumcision in a primary care setting. Clin Pediatr. 2006;45(1):49-54.

12. Searles JM, MacKinnon AE. Home-dilatation of the urethral meatus in boys. BJU Int. 2004;93(4):596-7.

13. Shaw R. A MEATAL DILATOR FOR, SELF-USE. The Lancet. 1957;269(6975):915.

14. Cheung CL, Looi T, Lendvay TS, Drake JM, Farhat WA. Use of 3-dimensional printing technology and silicone modeling in surgical simulation: development and face validation in pediatric laparoscopic pyeloplasty. Journal of surgical education. 2014;71(5):762-7.

15. Golab A, Smektala T, Kaczmarek K, Stamirowski R, Hrab M, Slojewski M. Laparoscopic Partial Nephrectomy Supported by Training Involving Personalized Silicone Replica Poured in ThreeDimensional Printed Casting Mold. Journal of laparoendoscopic advanced surgical techniques Part A. 2017:27(4):420-2.

16. Maddox MM, Feibus A, Liu J, Wang J, Thomas R, Silberstein JL. 3D-printed soft-tissue physical models of renal malignancies for individualized surgical simulation: a feasibility study. Journal of robotic surgery. 2018;12(1):27-33.

17. von Rundstedt FC, Scovell JM, Agrawal S, Zaneveld J, Link RE. Utility of patient-specific silicone renal models for planning and rehearsal of complex tumour resections prior to robot-assisted laparoscopic partial nephrectomy. BJU Int. 2017;119(4):598-604.

18. Priester A, Natarajan S, Le JD, Garritano J, Radosavcev B, Grundfest W, et al. A system for evaluating magnetic resonance imaging of prostate cancer using patient-specific 3D printed molds. American journal of clinical experimental urology. 2014;2(2):127-35.

19. Wu HH, Priester A, Khoshnoodi P, Zhang Z, Shakeri S, Afshari Mirak S, et al. A system using patientspecific 3D-printed molds to spatially align in vivo MRI with ex vivo MRI and whole-mount histopathology for prostate cancer research. Journal of magnetic resonance imaging: JMRI. 2019;49(1):270-9.

20. Porpiglia F, Checcucci E, Amparore D, Autorino R, Piana A, Bellin A, et al. Augmented-reality robotassisted radical prostatectomy using hyper-accuracy three-dimensional reconstruction (HA3D) technology: a radiological and pathological study. BJU Int. 2019;123(5):834-45.

21. Porpiglia F, Fiori C, Checcucci E, Amparore D, Bertolo R. Augmented Reality Robot-assisted Radical Prostatectomy: Preliminary Experience. Urology. 2018;115:184.

22. Shin T, Ukimura O, Gill IS. Three-dimensional Printed Model of Prostate Anatomy and Targeted Biopsy-proven Index Tumor to Facilitate Nerve-sparing Prostatectomy. European urology. 
2016;69(2):377-9.

23. Atalay HA, Canat HL, Ulker V, Alkan I, Ozkuvanci U, Altunrende F. Impact of personalized threedimensional - 3D-printed pelvicalyceal system models on patient information in percutaneous nephrolithotripsy surgery: a pilot study. Int Braz J Urol. 2017;43(3):470-5.

24. Bernhard JC, Isotani S, Matsugasumi T, Duddalwar V, Hung AJ, Suer E, et al. Personalized 3D printed model of kidney and tumor anatomy: a useful tool for patient education. World $\mathrm{J}$ Urol. 2016;34(3):337-45.

25. Chen MY, Skewes J, Woodruff MA, Rukin NJ. Using bespoke 3D-printed models to improve patient understanding of an encrusted ureteric stent. Journal of Clinical Urology. 2019:2051415819876514.

26. Kjaergaard B, Walter S, Bartholin J, Andersen JT, Nohr S, Beck H, et al. Prevention of urethral stricture recurrence using clean intermittent self-catheterization. British journal of urology. 1994;73(6):692-5.

27. Karunakaran KP, Suryakumar S, Pushpa V, Akula S. Retrofitment of a CNC machine for hybrid layered manufacturing. The International Journal of Advanced Manufacturing Technology. 2009;45(7):690703.

28. Park CJ, Kim HW, Jeong S, Seo S, Park Y, Moon HS, et al. Anti-Reflux Ureteral Stent with Polymeric Flap Valve Using Three-Dimensional Printing: An In Vitro Study. J Endourol. 2015;29(8):933-8.

29. del Junco M, Okhunov Z, Yoon R, Khanipour R, Juncal S, Abedi G, et al. Development and initial porcine and cadaver experience with three-dimensional printing of endoscopic and laparoscopic equipment. Journal of endourology. 2015;29(1):58-62.

30. Dall'Ava L, Hothi H, Di Laura A, Henckel J, Hart A. 3D Printed Acetabular Cups for Total Hip Arthroplasty: A Review Article. Metals. 2019;9(7).

31. Wojtyła S, Klama P, Baran T. Is 3D printing safe? Analysis of the thermal treatment of thermoplastics: ABS, PLA, PET, and nylon. Journal of Occupational Environmental Hygiene. 2017;14(6):D80-D5.

\section{Figures}




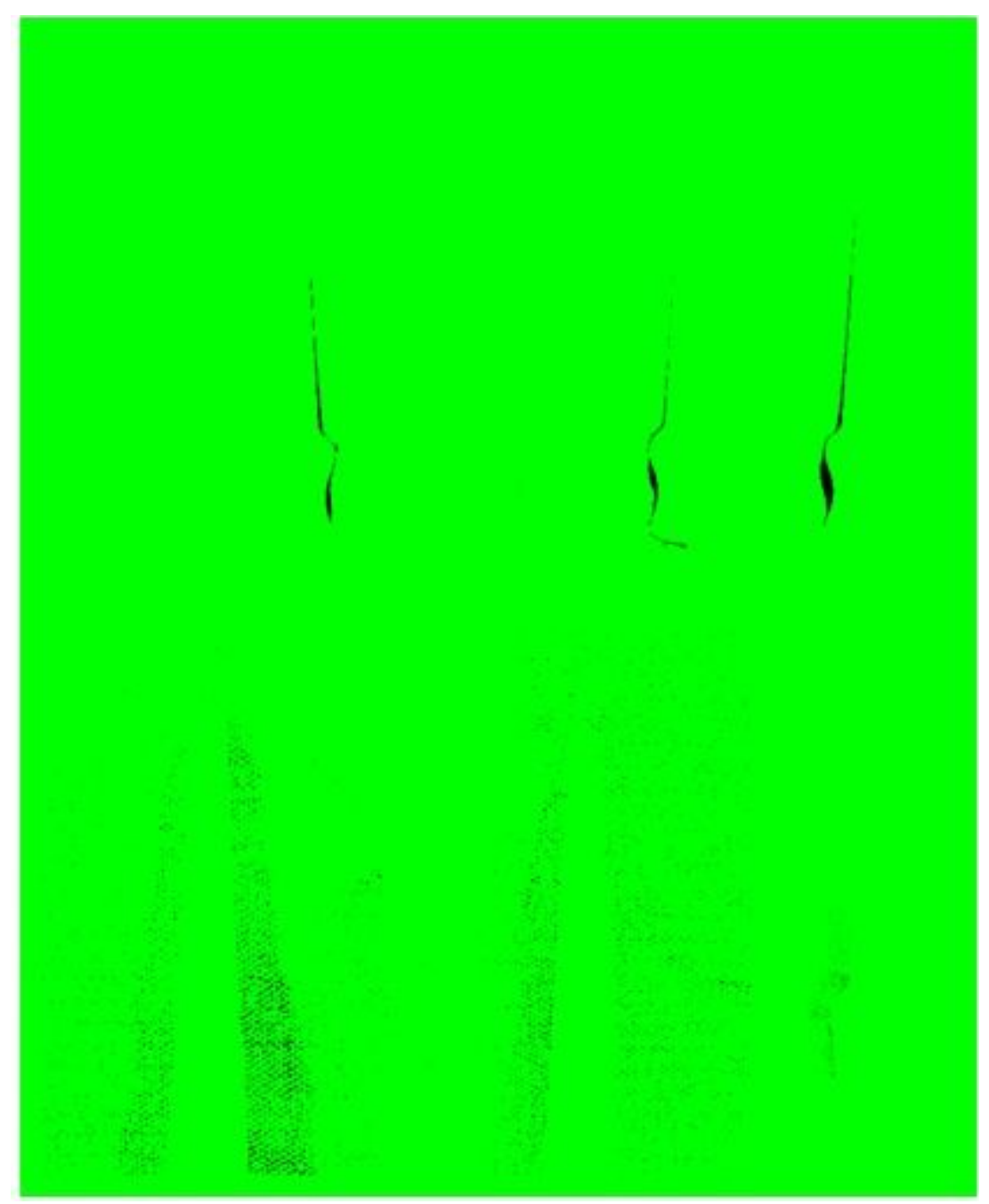

\section{Figure 1}

A: 3D printed meatal urethral dilators (left to right): commercial Cook@ meatal dilator, vertical PLA, vertical $A B S$, horizontal ABS, SLS nylon. B: Comparison in the 3D print quality of the tips of the vertically orientated ABS dilator (left) which shows notches on the left where imperfections have developed and horizontally orientated ABS dilator (right) which was printed with soluble support material and has a smoother result. C: Machined stainless steel dilator 


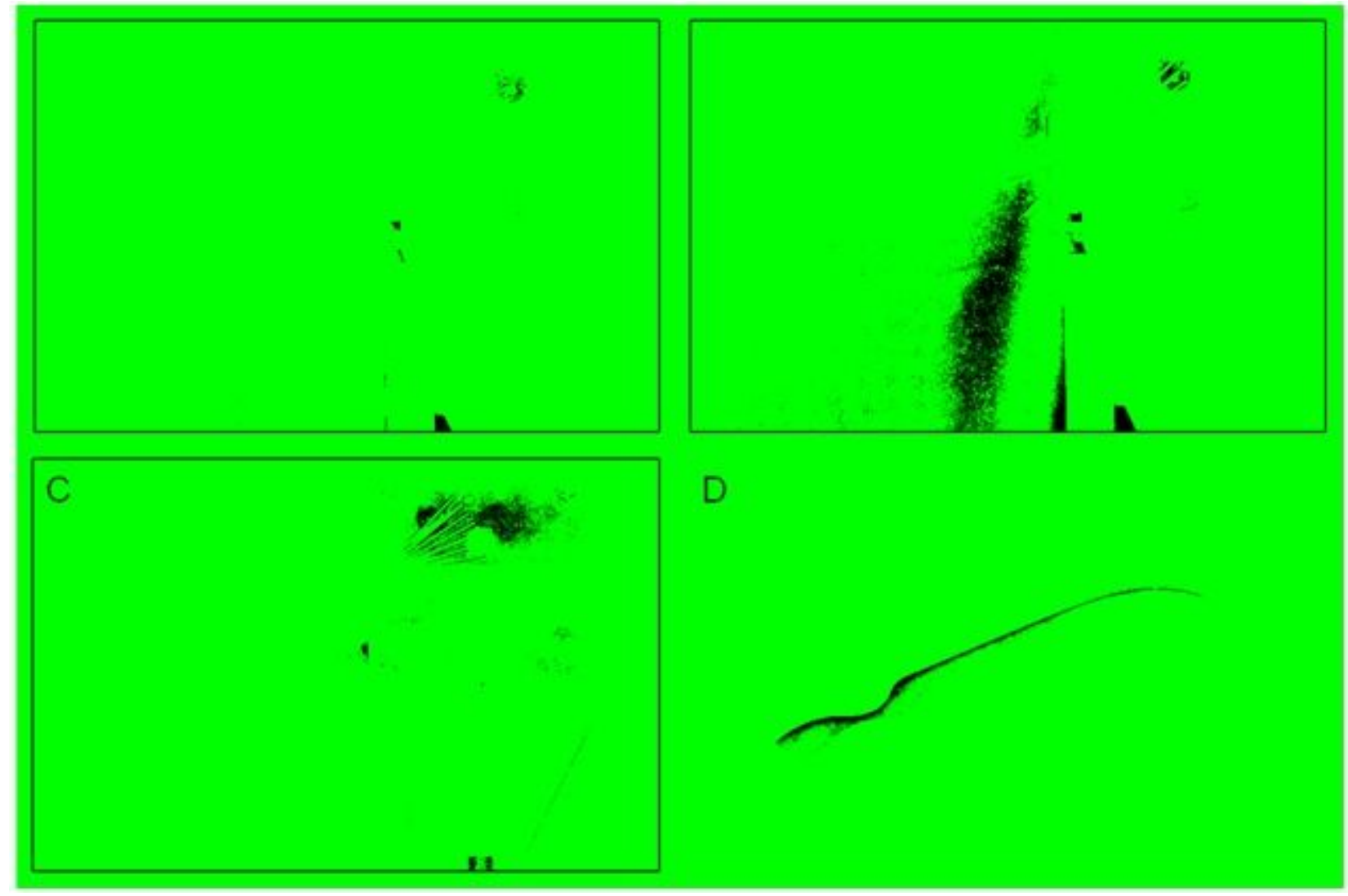

\section{Figure 2}

A freeze frame of the video the moment before the vertical PLA (A), vertical ABS (B) and horizontal ABS (C) dilators snapped. The approximate angle of bending before snapping was estimated as $10^{\circ}, 12^{\circ}$ and $40^{\circ}$ respectively. SLS nylon 3D printed dilator (D) after applying approximately $5 \mathrm{~kg}$ of manual pressure to the tip bent but did not break

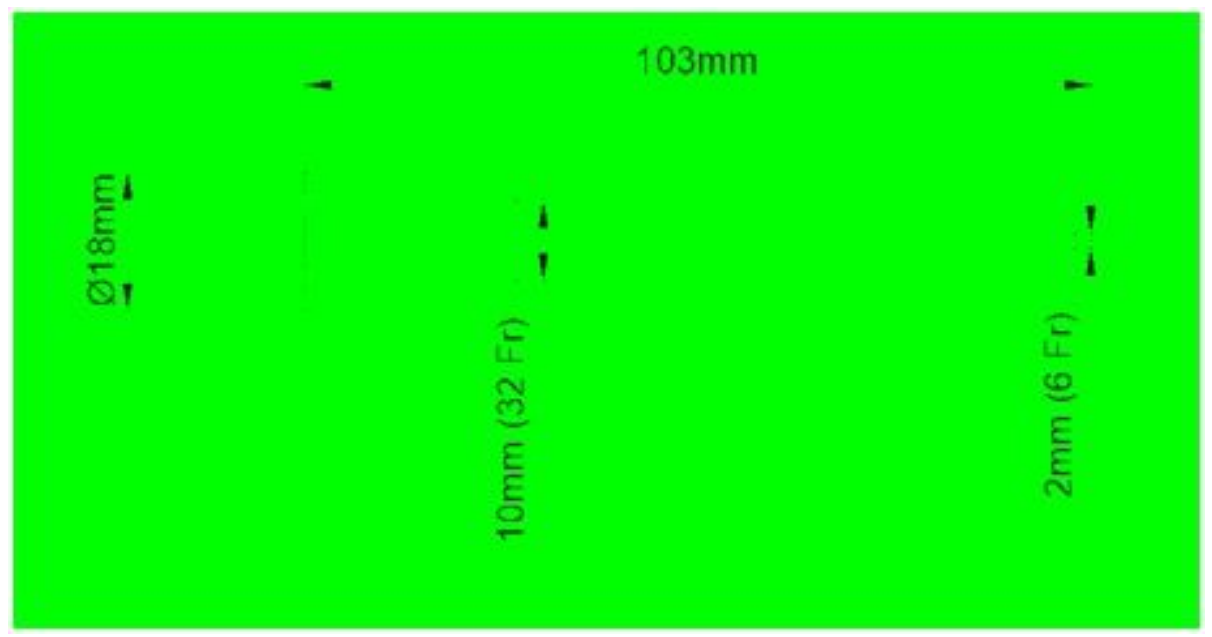

\section{Figure 3}

Prototype dilator design and dimensions in millimetres $(\mathrm{mm})$ and French $(\mathrm{Fr})$ 
Extrader

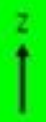

Vertical Dilator

Horizontal Dilator

Sipport

Build plate
1

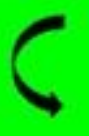

Heated Nozzle
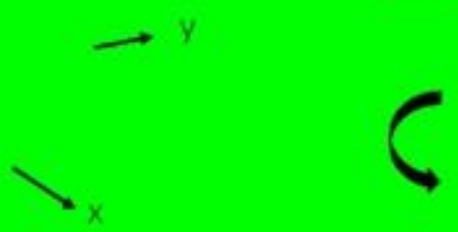
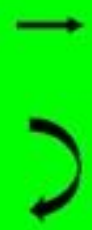

No cracks can easily form

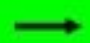

\section{Figure 4}

A comparison of how the orientation of the dilator in a FDM 3D printer can affect the mechanical strength at the tip. The vertically orientated 3D printed dilator (purple) will be more likely to snap completely due to the weakness between the layers compared to the horizontally printed dilator (yellow). However, the downside is that overhanging parts like the tip of the dilator when orientated horizontally requires printing of a support material. 


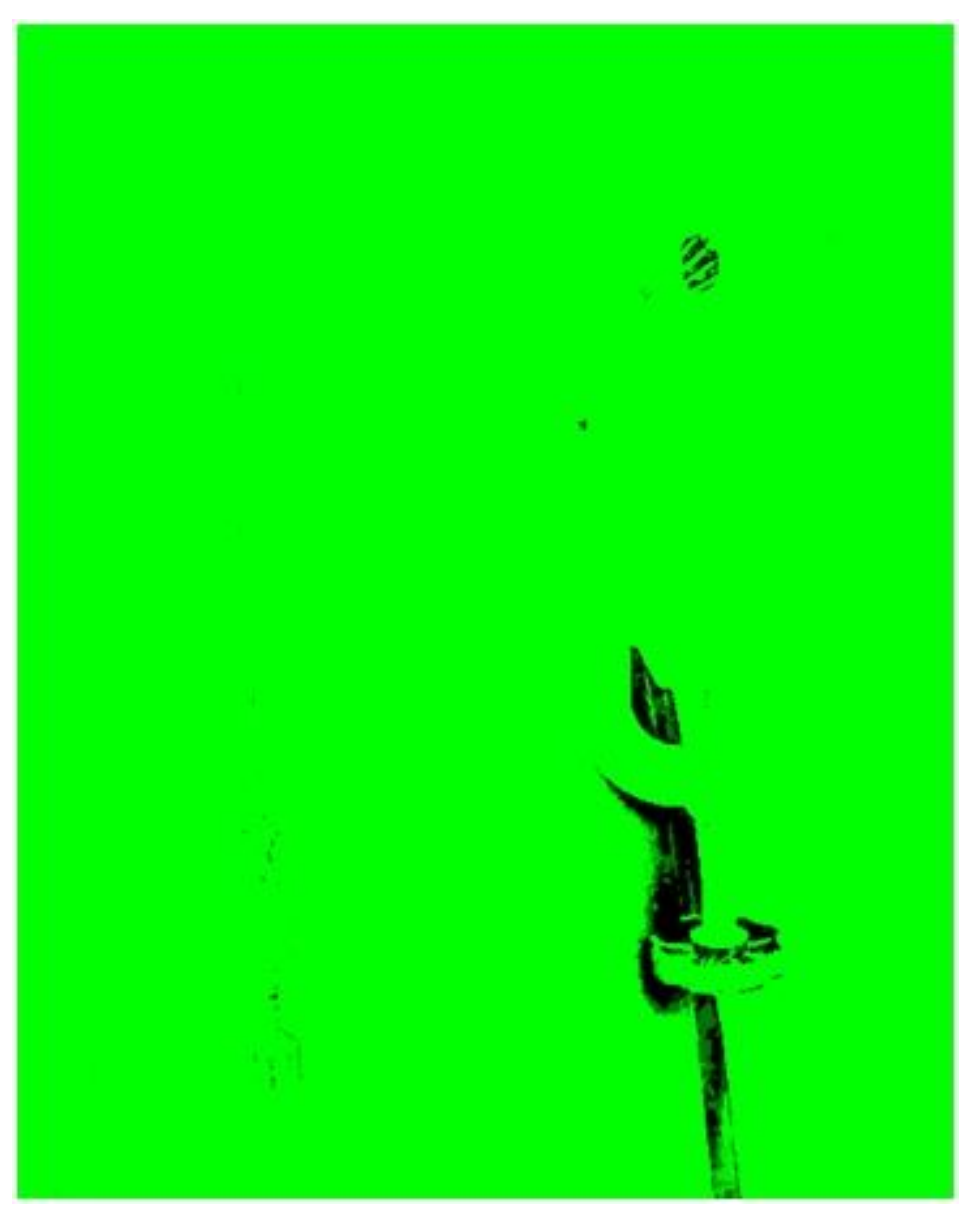

\section{Figure 5}

Setup for mechanical testing of dilators. Dilator inserted into custom laser-cut acrylic with markings for tip length and angles and held in place by vice. Calibrated weights are hung from handle of dilator. 